immunoglobulin heavy chain gene rearrangement and B-cell lymphoma 2 staining would be helpful to make the diagnosis clear ${ }^{4}$.

In summary, a diagnosis of CP should be considered when dermatologists encounter cases of asymptomatic neuronal pigment dermatosis. We speculate that further investigations on the association of the neural pathway with respect to the pathophysiology would be helpful to improve our understanding about CP.

\section{CONFLICTS OF INTEREST}

The authors have nothing to disclose.

\section{ORCID}

Joong-Heon Suh, https://orcid.org/0000-0002-1046-0487

Ho-Young Kim, https://orcid.org/0000-0002-1029-3287

Jae Ho Lee, https://orcid.org/0000-0002-3872-0527

Soo-Kyung Lee, https://orcid.org/0000-0002-7460-5657
Un-Ha Lee, https://orcid.org/0000-0003-1626-5583

Myoung-Shin Kim, https://orcid.org/0000-0002-0660-8098

\section{REFERENCES}

1. Uhara $H$, Saida $T$, Ikegawa $S$, Yamazaki $Y$, Mikoshiba $H$, Nijoh S, et al. Primary cutaneous plasmacytosis: report of three cases and review of the literature. Dermatology 1994; 189:251-255

2. Haque M, Hou JS, Hisamichi K, Tamada K, Cusack CA, Abdelmalek $\mathrm{M}$, et al. Cutaneous and systemic plasmacytosis vs. cutaneous plasmacytic castleman disease: review and speculations about pathogenesis. Clin Lymphoma Myeloma Leuk 2011;11:453-461.

3. Honda R, Cerroni L, Tanikawa A, Ebihara T, Amagai M, Ishiko A. Cutaneous plasmacytosis: report of 6 cases with or without systemic involvement. J Am Acad Dermatol 2013;68:978-985.

4. Han XD, Lee SSJ, Tan SH, Chong WS, Ng SK, Ooi MGM, et al. Cutaneous plasmacytosis: a clinicopathologic study of a series of cases and their treatment outcomes. Am J Dermatopathol 2018;40:36-42.

\title{
Expression of Human Herpes Virus 6, 7, Epstein-Barr Virus and Cytomegalovirus in Patients with Diverse Adverse Cutaneous Reactions to Drug
}

\author{
Young-Wook Ryoo, Joon-Bum Lee, Won-Oh Kim, Sung-Ae Kim \\ Department of Dermatology, Keimyung University School of Medicine, Daegu, Korea
}

Dear Editor:

Various drugs can cause diverse cutaneous adverse drug reactions $(\mathrm{CADR})^{1}$. Factors have been implicated in CADR, including the dosage, duration of use, physiological status and genetic background of the patient ${ }^{1}$. In addition, current or past viral infection has been reported to affect the occurrence of CADR ${ }^{2}$. In particular, many authors have suggested the activation of human herpes virus (HHV) 6 ,

Received March 18, 2019, Revised July 23, 2019, Accepted for publication August 7, 2019

Corresponding author: Sung-Ae Kim, Department of Dermatology, Keimyung University School of Medicine, 56 Dalseong-ro, Jung-gu, Daegu 41931, Korea. Tel: 82-53-250-7624, Fax: 82-53-250-7626, E-mail: skksasf@ hanmail.net ORCID: https://orcid.org/0000-0002-6040-6630

This is an Open Access article distributed under the terms of the Creative Commons Attribution Non-Commercial License (http://creativecommons. org/licenses/by-nc/4.0) which permits unrestricted non-commercial use, distribution, and reproduction in any medium, provided the original work is properly cited.

Copyright $($ The Korean Dermatological Association and The Korean Society for Investigative Dermatology 


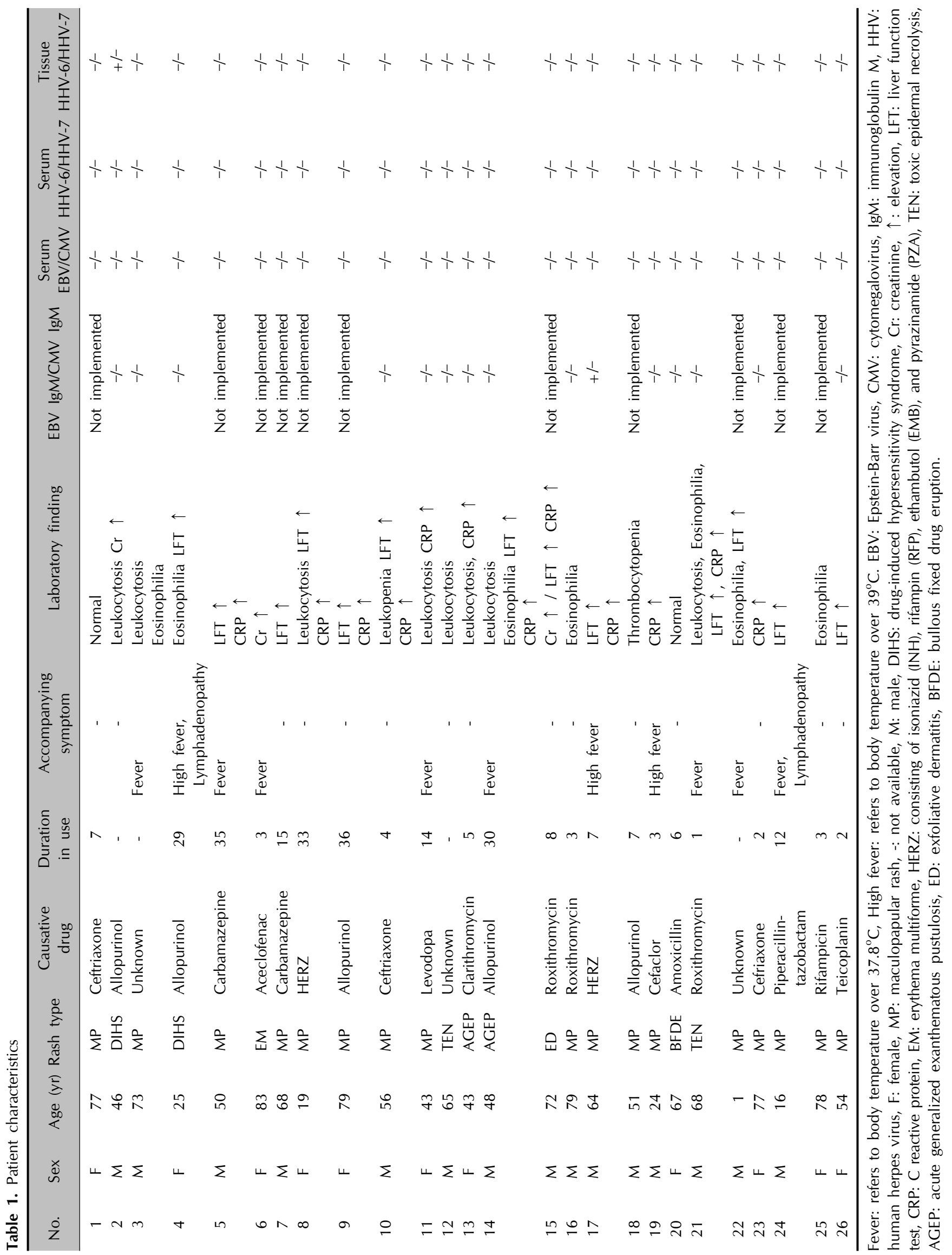


7, Epstein-Barr virus (EBV), and cytomegalovirus (CMV) in patients with drug-induced hypersensitivity syndrome $(\mathrm{DIHS})^{2,3}$. However, aside from DIHS, there are scarce data regarding the relationship of $\mathrm{HHV} 6,7, \mathrm{EBV}$, and $\mathrm{CMV}$ with the overall CADR. Herein, we report viral expression in patients showing various types of CADR in real clinical situations.

Data were analyzed for 26 consecutive patients diagnosed with CADR. The patients provided informed consent for participating in this study and the study was approved by the Institutional Review Board (no. 2016-10-033). The diagnosis was based on history of drug use and clinical features. The presence of HHV 6, 7, EBV, and CMV was confirmed from blood samples and tissue biopsy obtained from the patients $1 \sim 2$ days after appearance of the typical skin lesion. DNA was extracted using QIAamp DNA mini kit (Qiagen, Hilden, Germany) and paraffin-embedded tissues using the QIAamp ${ }^{\circledR}$ DNA FFPE Tissue kit (Qiagen), and amplified with real-time polymerase chain reaction (PCR) using primers for the EBV R-gene (Argene, Varihes, France) and the CMV, HHV 6, 7, 8R genes (Argene) with oasigTM 2x qPCR Mastermix (Thermofisher, Waltham, MA, USA) and a LightCycler system (Roche, Indianapolis, IN, USA). Serum EBV capsid antigen immunoglobulin $M$ (IgM) and anti-CMV IgM levels were also assessed.

The demographic characteristics and clinical and laboratory findings of the patients are summarized in Table 1. The most common cutaneous reaction was maculopapular exanthema (MPE), with two cases each of DIHS, acute generalized exanthematous pustulosis (AGEP), and toxic epidermal necrolysis, along with one case each of erythema multiforme, exfoliative dermatitis, and bullous fixed drug eruption. Drug allergy encompasses a spectrum of immunologically-mediated hypersensitivity reactions due to various mechanisms ${ }^{4}$. Especially, hypersensitivity reactions to drugs often presents with known immune-mediated reactions including fever, rashes, cytopenia, vasculitis and even anaphylaxis ${ }^{5}$. Cutaneous eruption with maculopapular rashes without fever and internal organ damage was diagnosed with MPE, and with fever or internal organ damage was diagnosed with DIHS as in two patients taking allopurinol. Patients with AGEP showed edematous diffuse erythema with multiple, sterile non-follicular pustules $^{6}$. The suspected causative agent was antibiotics in 11 cases: three involving ceftriaxone, three involving roxithromycin, and one each involving clarithromycin, cefaclor, amoxicillin, piperalcillin-tazobactam, and teicoplanin. Anti-tuberculosis drugs were suspected in three cases, including isoniazid, rifampin, ethambutol, and pyrazinamide. Other suspected drugs were allopurinol, carbamazepine, aceclofenac, and levodopa. Four patients reported simultaneous use of multiple drugs making it difficult to determine the causative agent. The period from drug administration to skin symptoms ranged from 1 day to 36 days, with an average of 13 days. Real-time PCR demonstrated negative results for HHV 6, 7, EBV, and CMV DNA in the blood samples of all patients. However, the tissue sample of one patient with DIHS was positive for HHV 6 . Only one patient was positive for the EBV capsid antigen IgM, who developed a MPE after taking anti-tuberculosis medication; none of the patients was positive for serum anti-CMV IgM.

Overall, we could not find direct evidence of an association of HHV 6, 7, EBV, and CMV with CADR, except for one patient with DIHS. The positive result for serum EBV capsid antigen IgM with negative EBV PCR in only one patient is not enough to conclude that there is a direct association between virus and $\mathrm{MPE}^{7}$. In previous study that investigated the association between CADR and HHV 6, EBV, and CMV except HHV 7, positive results were observed only in DIHS, but negative results in all MPE cas$\mathrm{es}^{2}$. The reason for the negative findings of almost all of the viral markers in this cohort is unclear. The blood and tissue samples might not have been obtained within an adequate window for detection. Alternatively, this might reflect a weak association between these viruses and overall CADR in contrast to the clear association of viral reactivation in the pathophysiology of DIHS, as suggested by a Japanese consensus group ${ }^{8}$. Thus, DIHS might represent a distinct disease entity to other CADR.

In conclusion, there is still no clinical proof of a relationship between reactivation of HHV 6, 7, EBV, and CMV and overall CADR, except DIHS. Inclusion of a larger number of samples and diverse timing of sampling would be needed to confirm our results.

\section{ACKNOWLEDGMENT}

This research was supported by the 2016 Bisa Research Grant of Keimyung University. The biological specimens and data used in this study were provided by the Keimyung University Dongsan Hospital Biobank, a member of the Korea Biobank Network.

\section{CONFLICTS OF INTEREST}

The authors have nothing to disclose.

\section{ORCID}

Young-Wook Ryoo, https://orcid.org/0000-0002-2477-6263 Joon-Bum Lee, https://orcid.org/0000-0002-7588-4678 
Won-Oh Kim, https://orcid.org/0000-0001-6826-6444

Sung-Ae Kim, https://orcid.org/0000-0002-6040-6630

\section{REFERENCES}

1. Abdullahi Rabiu A, Nordin Bin S, Mainul H. Adverse drug reactions: predisposing factors, modern classifications and causality assessment. Res J Pharm Tech 2014;7:1091-1098.

2. Ozcan D, Seçkin D, Bilezikçi B, Arslan H. The role of human herpesvirus-6, Epstein-Barr virus and cytomegalovirus infections in the etiopathogenesis of different types of cutaneous drug reactions. Int J Dermatol 2010;49:12501254.

3. Draz N, Datta S, Webster DP, Cropley I. Drug reaction with eosinophilia and systemic symptoms (DRESS) syndrome secondary to antituberculosis drugs and associated with human herpes virus-7 (HHV-7). BMJ Case Rep 2013;2013: bcr2013010348.

4. Warrington R, Silviu-Dan F, Wong T. Drug allergy. Allergy Asthma Clin Immunol 2018;14(Suppl 2):60.

5. Shepherd GM. Hypersensitivity reactions to drugs: evaluation and management. Mt Sinai J Med 2003;70:113-125.

6. Hoetzenecker W, Nägeli M, Mehra ET, Jensen AN, Saulite I, Schmid-Grendelmeier $\mathrm{P}$, et al. Adverse cutaneous drug eruptions: current understanding. Semin Immunopathol 2016; 38:75-86.

7. De Paschale M, Clerici P. Serological diagnosis of EpsteinBarr virus infection: problems and solutions. World J Virol 2012;1:31-43.

8. Shiohara T, lijima M, Ikezawa Z, Hashimoto K. The diagnosis of a DRESS syndrome has been sufficiently established on the basis of typical clinical features and viral reactivations. Br J Dermatol 2007;156:1083-1084. 